\title{
A Novel Approach to Determine the Non-Dimensional Heliostat Field Boundary for Solar Tower Plants
}

\author{
Srilakshmi Gopalakrishnan ${ }^{\mathrm{a}}$; Suresh N S ${ }^{\mathrm{b}}$; Thirumalai N C ${ }^{\mathrm{c}}$; M A Ramaswamy ${ }^{\mathrm{d}}$ \\ ${ }^{a}$ Corresponding Author: Research Engineer, \\ Phone: +91 (80) 66902594, E-mail: srilakshmi@ cstep.in \\ ${ }^{\mathrm{b}} \mathrm{Sr}$. Research Engineer, \\ Phone: +91 (80) 66902536, E-mail: suresh@cstep.in \\ ${ }^{\mathrm{c}}$ Research Scientist, \\ Phone: +91 (80) 66902505, E-mail: thirumalai@ cstep.in \\ d Advisor, \\ Phone: +91 (80) 66902554, E-mail: mar@cstep.in
}

Address: Center for Study of Science, Technology and Policy (CSTEP), $10^{\text {th }}$ Cross, Papanna Layout, Mayura Street, Outer Ring Road, Bengaluru, Karnataka, India -560 094.

\begin{abstract}
Solar tower technology has gained considerable momentum over the past decade. In a solar tower plant, the power collected by the heliostat field is strongly coupled to the height of the tower and its location with respect to the field. This paper provides a methodology to fix the boundary of the field (non-dimensionalised with respect to the tower height). While developing this methodology, it was realised that one needs to have an estimation of the nominal variation of packing density with nondimensional distance of the heliostat from the tower base. Packing density is fixed during the design of the field. A nominal variation of packing density was obtained by studying three existing plants which use radial staggered field patterns. This packing density data was used to arrive at contours of equal annual energy per unit land area $\left(e_{l}\right)$. This approach was then evaluated qualitatively and verified quantitatively with non-dimensional solar fields of existing plants. Based on these comparisons, it is suggested that for preliminary analysis, a seed value of $e_{l}=0.16 \mathrm{MWh} / \mathrm{m}^{2}$ may be used as a nominal value to set the field boundary. The significance of coupling of the solar field boundary with tower height is also discussed.

Keywords: Solar Tower; Heliostat Field Boundary; Packing Density; Energy Contours
\end{abstract}




\section{Nomenclature}

\begin{tabular}{|c|c|}
\hline$A_{\text {heliostat }}$ & Area of heliostat, $\mathrm{m}^{2}$ \\
\hline \multirow[t]{2}{*}{$D N I_{i}$} & Hourly Direct Normal Irradiance at the location for the $i^{t h}$ hour, W/m \\
\hline & Total land area, $\mathrm{m}^{2}$ \\
\hline$N_{f}$ & Number of points inside the field boundary \\
\hline$M A_{n}$ & Total mirror area of $n^{\text {th }}$ row, $\mathrm{m}^{2}$ \\
\hline$L A_{n}$ & Total land area of $n^{\text {th }}$ row, $\mathrm{m}^{2}$ \\
\hline$P D_{p}$ & Packing density at point $p$, Ratio of the mirror area to land area. \\
\hline$P_{s, d}$ & Design solar power of plant, $\mathrm{W}$ \\
\hline$S M$ & Solar Multiple \\
\hline$d_{x} / h$ & Non-dimensionalised grid spacing in $\mathrm{x}$ direction \\
\hline$d_{y} / h$ & Non-dimensionalised grid spacing in y direction \\
\hline$e_{l}$ & $\begin{array}{l}\text { Annual reflected energy per unit land area (taking into account cosine effect and } \\
\text { packing density), } \mathrm{Wh} / \mathrm{m}^{2}\end{array}$ \\
\hline$e_{m}$ & $\begin{array}{l}\text { Annual reflected energy per unit mirror area of field (taking into account only cosine } \\
\text { effect), } \mathrm{Wh} / \mathrm{m}^{2}\end{array}$ \\
\hline$h$ & Height of the tower, $\mathrm{m}$ \\
\hline$h[1]$ & Height of the tower at Solar Multiple $=1, \mathrm{~m}$ \\
\hline$i$ & Number of the hour (varies from 1 to 8760 ) \\
\hline$n_{n}$ & Number of heliostats in $n^{\text {th }}$ row \\
\hline$p$ & Point in the field \\
\hline$r$ & Radial distance from base of tower to point in field, $\mathrm{m}$ \\
\hline$r_{n-1}$ & Radial distance from base of tower to the $(n-1)^{\text {th }}$ row of heliostats, $\mathrm{m}$ \\
\hline$r_{n}$ & Radial distance from base of tower to the $n^{\text {th }}$ row of heliostats, $\mathrm{m}$ \\
\hline$r_{n+1}$ & Radial distance from base of tower to the $(n+1)^{\text {th }}$ row of heliostats, $\mathrm{m}$ \\
\hline$r / h$ & Non-dimensionalised radial distance of point $(x / h, y / h)$ from the tower \\
\hline$\left(\frac{r}{h}\right)_{\min }$ & Minimum non-dimensional distance from tower \\
\hline$x / h$ & Non-dimensionalised $x$ coordinate of point in field w.r.t tower height \\
\hline$y / h$ & Non-dimensionalised $y$ coordinate of point in field w.r.t tower height \\
\hline$\Delta \theta$ & Angle subtended by farthest two heliostats of a row, radians \\
\hline$\Delta \varnothing$ & Circumferential angle between heliostat centres, radians \\
\hline$\phi$ & Latitude of the location, degrees \\
\hline
\end{tabular}


$\theta_{i}$

$\theta_{i, p}$

$\eta_{m}$

$\eta_{s-e}$

Angle of incidence of the sun for hour $i$

Angle of incidence of the sun for hour $i$ and point $p$

Efficiency of the heliostat

Solar to electric conversion efficiency 


\section{Introduction}

A solar tower uses a large number of heliostats or mirrors to reflect solar energy incident on them, onto a receiver that is located at the top of a tower. The concentrated solar energy that falls on the receiver is transferred to a Heat Transfer Fluid (HTF) which passes through the receiver. The thermal energy of the HTF is then transferred to a working fluid in the power block, by means of a heat exchanger, thereby generating electricity. Fig. 1 shows the schematic diagram of a solar tower plant.

The goal of the present study is to define a rational methodology to fix the boundary of the solar field of a Concentrated Solar Power (CSP) plant using solar tower technology. The objective is to obtain a non-dimensional radial field boundary as a function of azimuth, taking into account the latitude of the location, hourly DNI data as well as packing density. This is required in order to develop a method for the preliminary design of a solar tower plant that is analogous to that which was done for the design of a parabolic trough plant (of given capacity, thermal storage hours and hybridisation) [1].

Though there are a number of articles dealing with solar tower plants, they all deal with either characterisation and performance studies of existing plants [2-5], detailed design of heliostat field, given the heliostat and tower details, and optimisation [6-8] also using proposed spiral layouts [9] or detailed flux distribution on a receiver [10-11]. Analyses on ray tracing methods for simulation, shadowing and blocking due to adjacent heliostats and analyses on heliostat images have been performed [12-14]. Reviews of the various components in this technology as well as existing plants (in operation and under construction) have been performed [15-16]. However, information in open literature on the method to be followed for preliminary optimum design of a solar tower plant is very scarce. A chapter in [17] provides empirical guidance in the preliminary sizing and specification of the heliostat field. However, it does not provide a method for fixing the solar field boundary in order to carry out the preliminary design of solar tower plant analogous to what is developed for a parabolic trough plant [1], where the design is optimised to get maximum solar to electric conversion efficiency $\left(\eta_{s-e}\right)$. This paper attempts to develop a systematic method to fix the solar field boundary necessary for preliminary design of a solar tower plant.

Section 2 discusses the need for coupling between the solar field boundary and the tower height (i.e. height at which the receiver is located) in non-dimensional terms. Section 3 discusses the assumptions on which the methodology is based. Section 4 deals with the rationale for choosing contours of equal energy per unit land area $\left(e_{l}\right)$ to guide the choice of non-dimensional solar field boundary. The results of the method, applied to four typical locations, are given in Section 5 to show that equal $e_{l}$ contours qualitatively exhibit the expected variation of the non-dimensionalised radial distance of a heliostat from the tower base $(r / h)$ with azimuth, with respect to changes in latitude and Direct Normal Irradiation (DNI). Section 6 deals with the choice of field boundary. Concluding remarks are made in Section 7.

\section{Need for Coupling of Tower Height and Solar Field Boundary}

In solar tower technology, the complexities involved in estimating the energy obtained from the field are listed as follows:

- The cosine effect of each heliostat is different and depends on $r / h$, azimuth position and time of the day

- The shadowing and blocking effects vary for every heliostat. These effects depend on the heliostats $r / h$ and azimuth position as well as the spacing of neighbouring heliostats.

Therefore, in assessing the power and energy that can be collected by any heliostat, a nominal packing density effect has to be considered.

It is clear that the two effects listed depend on $r / h$ and azimuth angle of the heliostat. 
For a given tower height to choose the corresponding surround solar field, in order to avoid the process of choosing the boundary in a time consuming optimisation process, one has to fix the nondimensionalised boundary value $(r / h)$ in terms of the azimuth angle. The boundary in the North, South East and West directions needs to be obtained. In other words, the tower height and solar field are essentially related.

Therefore, developing a rational method to couple the surround solar field boundary with tower height in terms of the variation of non-dimensional parameter $r / h$ with azimuth angle is essential for the preliminary design of the solar tower plant. The method has to take into account the latitude of the location, DNI data and packing density of the heliostats (to minimise blockage and shadow effects).

The coupling is independent of the plant capacity. Once this nominal non-dimensional coupling is established, the height of the tower, corresponding to Solar Multiple (SM) equal to 1 and the corresponding solar field can be determined by equating the reflected solar power from the field, at the best hour of the year, to the design solar power required from this field to generate the design electrical power. Then, for various values of $S M$, the corresponding height $(h[S M]=h[1] \times \sqrt{S M})$, electrical energy generated and $\eta_{s-e}$ or least Levelised Cost of Electricity (LCOE) can be determined. The $S M$ value corresponding to the highest $\eta_{s-e}$ or LCOE is then used to determine the optimum height and corresponding solar field. Therefore, this enables the extension of parabolic trough plant design method to solar tower plants. However, this paper is confined to the development of a method to determine and fix the non-dimensional heliostat field boundary.

\section{Assumptions of Methodology}

The methodology developed is assumed to have a radial staggered heliostat field configuration.

The number of variants in solar tower plant components, namely, the heliostats, Heat Transfer Fluids (HTFs), types of receivers and field configurations are many. The heliostat field can either have a radial staggered, cornfield or spiral layout. When a radial staggered field pattern is used, it could use a surround field, corresponding to an external cylindrical receiver or be restricted to a single side field which is the case when a cavity receiver is used. A cornfield pattern generally employs a constant packing density of heliostats and therefore, the shadowing and blocking losses are high.

Moreover, from a review conducted on the existing solar tower plants, out of about $615 \mathrm{MW}$ (the total installed capacity worldwide), more than about $90 \%$ of these plants have a surround field with a radial staggered configuration. Therefore, developing a method for this type of solar field was considered to be most relevant.

\section{Rationale for Choosing Equi-Energy Contours per Unit Land Area}

Having established the need and advantages of coupling the heliostat boundary with the tower height, a rational method to obtain this boundary is discussed in this section.

There are two aspects to fixing the non-dimensionalised field boundary. The first is the relative variation of $r / h$ with azimuth and the second is the magnitude of the maximum $r / h$ up to which the boundary has to be limited from economic considerations. In order to find the relative $r / h$ variation with azimuth, contours of constant energy values that can be extracted from unit area of the heliostat field, need to be determined. As $r / h$ increases, the value of energy contours decreases and becomes uneconomical at some point. The energy level beyond which it is considered uneconomical has to be eventually determined.

Solar energy that can be collected by unit area of the heliostat mirror, $e_{m}$, located at a point $p$, from the tower at any hour $i$, out of the 8760 hours of a Typical Meteorological Year (TMY) is given by $D N I_{i}$ $\times \cos \theta_{i, p}$. Here, $D N I_{i}$ corresponds to DNI at hour $i$ in $\mathrm{W} / \mathrm{m}^{2}$ [18] and $\theta_{i, p}$ is the angle between the normal to the mirror and both the incident ray from the sun as well as the reflected ray from the mirror 
to the receiver. The methodology to calculate $\theta_{i, p}$ and subsequently, $\cos \theta_{i, p}$, the cosine effect, is given in [19].

Consequently Eq. 1 then gives the annual solar energy, $e_{m}$, in $\mathrm{MWh} / \mathrm{m}^{2}$, that can be captured and delivered to the receiver per unit area of heliostat mirror located at point $p$. A factor of $10^{-6}$ has been used in order to express this term in $\mathrm{MWh} / \mathrm{m}^{2}$.

$e_{m}=\left\{\left(\sum_{i=0}^{8760} D N I_{i} \times \cos \theta_{i, p}\right)\right\} \times 10^{-6}$

In the heliostat field, particularly with radially staggered arrangement, mirrors are spaced apart both circumferentially and radially to minimise the shadowing and blocking effects of adjacent heliostats. Therefore, the local packing density of the mirrors or heliostats (which is the fraction of the local area occupied by the mirror relative to the local land area), generally decreases as $r / h$ increases.

The annual energy that can be captured per unit mirror area $\left(e_{m}\right)$ does not represent the annual energy that can be captured per unit area of solar field (land area). In order to get the latter, $e_{m}$ from point $p$, has to be multiplied with the local packing density at that point. Therefore, a nominal variation of packing density with $r / h$ is needed.

To get this, the local packing density variations of three plants - Gemasolar, Planta Solar (PS) 10 and PS 20 were studied. Based on this, three conditions have been obtained for the variation of $P D_{p}$, the local packing density at point $p$, with $r / h$. These are given in Eq. 2 to Eq. 4.

$$
\begin{aligned}
& (P D)_{p}=0 \quad \text { for } \frac{r}{h}<\left(\frac{r}{h}\right)_{\text {min }} \\
& (P D)_{p}=0.492-0.0939 \frac{r}{h} \quad \text { for }\left(\frac{r}{h}\right)_{\text {min }} \leq \frac{r}{h} \leq 2.8 \\
& (P D)_{p}=\frac{0.6}{\sqrt{\left(\frac{r}{h}\right)^{2}-1}} \text { for } \frac{r}{h}>2.8
\end{aligned}
$$

Details on how these relations were arrived at, are discussed in Appendix A.

The annual energy captured per unit land area of the solar field, $e_{l}$, in $\mathrm{MWh} / \mathrm{m}^{2}$ at point $p$ is given by Eq. 5.

$e_{l}=\left\{(P D)_{p} \sum_{i=0}^{8760} D N I_{i} \times \cos \theta_{i, p}\right\} \times 10^{-6}$

Fig. 2 gives the variation of $e_{l}$ with respect to $r / h$ in all the four directions for a typical location (Seville, Spain). The East and West direction curves overlap since the input DNI data is symmetrical for the morning and afternoon hours.

It is seen that as $r / h$ is increased in every direction, the energy from the field per unit land area $\left(e_{l}\right)$, gradually decreases. For example, if an energy value of $0.3 \mathrm{MWh} / \mathrm{m}^{2}$ is desired from the plant, the non-dimensional boundary on the North and South directions are approximately 3.7 and 2.7. The $r / h$ values along the East and West are the same and is about 3.2. This can be observed from Fig. 2. It is rational to fix the field boundary based on a certain $e_{l}$ contour. Determination of these contours is discussed in the Section 4.1.

It may be noted that from economic considerations, it is impossible to completely avoid shadowing and blocking losses, but by providing the local packing density variation with $r / h$, these losses are highly minimised and can be ignored in the preliminary first cut design. 
It may also be noted that in addition, if the actual inclined distance between the heliostat and receiver is high (of the order of a kilometre or more), then attenuation losses will be significant. Since attenuation effects depend on the actual physical distance as well as local site conditions, it cannot be considered in defining a general non-dimensional boundary. But its effect will be taken into account in computing the performance of the plant and in the preliminary design of the plant (after the solar field boundary has been fixed).

\subsection{Determination of Equi-Energy Contours}

A heliostat field having a range of $x / h$ and $y / h$ values from -10 to +10 is considered and grid points with a spacing of $d_{x} / h$ and $d_{y} / h$ along the $x / h$ and $y / h$ directions are used to determine the annual energy per unit land area of the field at each of these grid points using Eq. 5. It is assumed that the field does not extend beyond $r / h=10$. However, there is a particular point at which this energy is the highest. If one considers a plant location in the northern hemisphere, the highest energy point will be to the north of the tower and vice versa for southern locations. Contours of equal annual energy per unit land area which surround this point are obtained. From these contours, the outer heliostat field boundary corresponding to a chosen value can be fixed based on economic factors by performing a sensitivity analysis.

The non-dimensional heliostat field boundary is fixed once the value of $e_{l}$ contour is chosen.

The actual design of a solar field for a given capacity and number of storage hours, amounts to determining just the height of the solar tower. The actual solar field gets determined from the coupling between the tower height and the solar field through this non-dimensional boundary. For more details one can refer to [20].

\section{Results of Application of Methodology to Typical Locations}

Equi-energy contours based on unit land area, as described in the previous section, were obtained for four locations - Seville, Spain $\left(37.38^{\circ} \mathrm{N}\right)$, Tonopah, Nevada, US $\left(38.07^{\circ} \mathrm{N}\right)$, Brazil, South America ($\left.1.38^{\circ} \mathrm{N}\right)$ and Melbourne, Australia $\left(-37.67^{\circ} \mathrm{N}\right)$. The respective contours are shown from Fig. 3 to Fig. 6. The hourly DNI data for these locations were taken from [18].

The numbers shown on the contours are in annual $\mathrm{MWh} / \mathrm{m}^{2}$. The values of the annual DNI in $\mathrm{MWh} / \mathrm{m}^{2}$ and latitude at those locations are also indicated in the figures.

Seville and Tonopah are nearly at the same latitude. Therefore, their energy contours are similar. However, the boundary corresponding to $0.1 \mathrm{MWh}$ is larger for Tonopah, compared to that for Seville, since the DNI value at Tonopah is higher than that at Seville. This dependence on DNI is even more dramatically illustrated for Brazil and Melbourne, where the $0.1 \mathrm{MWh}$ contour is considerably smaller, corresponding to the much lower DNI values at these locations.

It may be noted that irrespective of which energy contour value one might choose for the boundary, for the northern locations, the boundaries extend more towards the north and for locations in the southern hemisphere, it extends further to the south. For the equator, it is symmetric. Therefore, qualitatively, this approach is reasonable.

From this analysis, it is clear that choosing an appropriate value of $e_{l}$ for fixing the boundary of the solar field is qualitatively reasonable. But the actual value to be chosen has to be based on economic considerations, which depends on various parameters like relative cost of various components, interest rates etc. Therefore, to choose a nominal value and range of values that can be permitted in the design methodology, one has to take recourse to compare the actual boundary of some exiting plants with the corresponding energy contours for that place and take a decision. 


\section{Choice of the Field Boundary}

In the previous section, the validity of the method was demonstrated qualitatively. In this section, comparison between the contour corresponding to the best choice of $e_{l}$ with actual plant boundary for a few cases is shown in order to assess:

a) Quantitative comparison of variation of $r / h$ boundary with azimuth angle

b) Nominal value to be chosen for $e_{l}$ for use in the general design methodology for solar tower.

To address a), solar field boundaries of two plants, namely Gemasolar (in Seville) and Crescent Dunes (in Tonopah) have been used and the results are presented in Fig. 7 and Fig. 8.

To address b), in addition to the two plants mentioned above, PS 10 and PS 20 (both in Seville) have also been considered since they also use radial staggered fields (even though they are single side fields). Since boundary value of $e_{l}$ is based on economic considerations it was felt worthwhile to have this additional data. These results are presented in Fig. 9 and Fig. 10.

From the figures, one can say that the appropriate equi-energy contour compare reasonably well, even quantitatively with the actual boundaries used in existing plants. Gemasolar and PS 20 field boundaries seem to match with a contour value (in $\mathrm{MWh} / \mathrm{m}^{2}$ ) of 0.18 , Crescent Dunes with 0.145 and PS 10 with 0.155 . The difference or offset between the $e_{l}$ contours and the actual plant boundaries could be due to differences in the variation of packing density with $\mathrm{r} / \mathrm{h}$ considered as well as the source of hourly DNI data points taken in the calculation of $e_{l}$ contours.

Based on this observation, a possible seed value for the energy value per unit land area as the nominal boundary value can be that corresponding to an $e_{l}$ value of $\sim 0.16( \pm 0.02)$, for the general preliminary design for solar tower plants. In the detailed design one can do a sensitivity analysis on this number and choose the optimum value based on iterations.

For a given capacity of plant, the design solar power, $P_{s, d}$, to be obtained from the field can be calculated if all the related efficiencies such as that for the power block, heat exchanger, heliostat etc. are known.

Once the field boundary is fixed in non-dimensional terms, the height of the tower, for a given capacity of the plant, at Solar Multiple $(S M)=1$ can be calculated using Eq. 6 :

$$
h[1]=\sqrt{\frac{P_{s, d}}{\left(\frac{d_{x}}{h} \times \frac{d_{y}}{h}\right) \times \eta_{m} \sum_{p=1}^{N_{f}} D N I_{i} \times \cos \theta_{i, j} \times P D_{p} \times \eta_{a t t, p}}}
$$

where $d_{x} / h$ and $d_{y} / h$ are non-dimensionalised grid spacings used in computation, $\eta_{m}$ is the efficiency of the heliostat, $\eta_{a t t, p}$ is the attenuation efficiency from point $p$ in the heliostat field, $N_{f}$ is the number of points under the boundary and $i$ is the hour (out of 8760 hours) for which $\left\{\sum_{p=1}^{N_{f}} D N I_{i} \times \cos \theta_{i, j} \times\right.$ $\left.P D_{p} \times \eta_{a t t, p}\right\}$ is maximum. Since $\eta_{\text {att }, p}$ depends on $h[1]$, initially, $h[1]$ is calculated taking $\eta_{\text {att, } p}$ as 1 and then by iteration, the converged value of $h[1]$ is determined. Details can be referred to in [20]. It is to be noted here that the heliostat or mirror efficiency, $\eta_{m}$, takes into account all factors such as reflectivity of mirror, tracking error, dirt/dust on mirrors, intercept factor etc.

With the solar field corresponding to $S M=1$, the power generated will be less than the design capacity at all hours other than the peak hour. Therefore, the solar field design involves choosing an optimum solar field with $S M$ greater than 1, after taking into account the storage and hybridisation constraints. The height at a given $S M, h[S M]$ is determined using Eq. 7. 


$$
h[S M]=h[1] \times \sqrt{S M}
$$

Once the height is determined, the actual field boundary is determined (because the maximum $r / h$ value in all directions was fixed earlier based on the chosen contour value). Therefore, the annual electrical energy generated and the total mirror area of the field are computed. The solar energy input is considered as (Annual DNI $\times$ Mirror Area). Thereby, value of $\eta_{s-e}$ is defined as a ratio of the annual electrical energy generated to the solar energy input. The consideration for determining the optimum $S M$ can be either the highest $\eta_{s-e}$ or the minimum LCOE, if cost inputs are available. A detailed explanation of this can be referred to in [20].

In order to arrive at the actual non-dimensional field boundary, a range of $e_{l}$ values can be chosen initially (around the seed value) and once the corresponding physical fields are identified, the economic parameters or LCOE indicators will determine the optimum required. The final field can be arrived at after performing an analysis to see how sensitive the economic parameters are to the $e_{l}$ values chosen.

\section{Conclusion}

In the absence of defining a non-dimensional solar field boundary, the design of a solar field for a CSP plant using solar tower technology (with external cylindrical or cavity receivers) would have to be done in a makeshift manner which is not rational.

In this paper, a method for coupling the solar field and tower height has been discussed and this method has been used to plot contours of constant energy per unit land area in the nondimensionalised solar field. A value of $\sim 0.16( \pm 0.02)$ has been suggested as a starting value (initial seed value) for preliminary design based on comparison with existing plants that are producing power commercially. The final boundary is determined based on an iterative process for $e_{l}$ and sensitivity analysis for each particular case.

Using this method, it has been possible to develop a rational methodology for the design of a solar field for a CSP plant using solar tower technology with surround fields using radial staggered field patterns [20] similar to that developed for parabolic trough technology. As stated earlier, the boundary value should be based on plant economics and perhaps needs to be fixed after conducting a sensitivity analysis on the contour value.

\section{Acknowledgement}

This paper is based on the work done at CSTEP supported in part under the US-India Partnership to Advance Clean Energy-Research (PACE-R) for the Solar Energy Research Institute for India and the United States (SERIIUS), funded jointly by the U.S. Department of Energy (Office of Science, Office of Basic Energy Sciences, and Energy Efficiency and Renewable Energy, Solar Energy Technology Program, under Subcontract DE-AC36-08GO28308 to the National Renewable Energy Laboratory, Golden, Colorado) and the Government of India, through the Department of Science and Technology under Subcontract IUSSTF/JCERDC-SERIIUS/2012 dated 22 ${ }^{\text {nd }}$ November, 2012. The authors are grateful to Dr Anshu Bharadwaj, Executive Director, CSTEP for his constant support and guidance. The authors would also like to thank Dr. Mridula Dixit Bharadwaj, Principal Research Scientist, CSTEP for her encouragement and Dr. V S Chandrasekaran, Advisor, CSTEP and Dr. Jai Asundi, Research Coordinator, CSTEP for their critical review in improving the manuscript. 


\section{Appendix A}

\section{Determination of Packing Density Variation}

For a solar tower plant, the concept of packing density is used to define and get an idea about how the heliostats are packed in the given land.

This is especially important in the case of a solar tower plant because the mirrors are all placed such that shadowing and blocking effects of adjacent heliostats are minimised. Consequently packing density varies with location in the solar field. The definition of local packing density is given by Eq. A.1.

$$
\text { Local Packing Density }=\left(\frac{\text { Mirror Area }}{\text { Land Area }}\right)_{\text {local }}
$$

In other words, it indicates the extent of utilisation of mirrors as a fraction of the local land area.

The local packing density in general is a function of $r / h$ for all existing plants having a radial staggered pattern.

The solar power received per unit area of the land depends on packing density. The average overall packing density for different plants can be calculated with the information available in present literature [21]. But, the variation of packing density with respect to $r / h$ is not given.

The variation of packing density with $r / h$ based on a theoretical layout of a solar field [19] was examined. In addition to this the fields of three existing solar tower plants - Gemasolar [22], PS 10 and PS 20 [23] were studied and replicated in excel.

\section{Field Replication}

The Gemasolar plant in Spain shown in Fig. A.1a is an existing operational solar tower plant using an external cylindrical receiver and surround field. This field has 2650 heliostats with a larger north side.

On closer examination, it is noted that there are 38 circular rows. The first 27 rows form complete circles around the tower. However the next 10 rows do not form complete circles around the tower. They stop at varying distances with the major part in the north side of the field.

Using Wikimapia, the radial distance of each row was measured. Additionally, the total number of heliostats were counted in each row. Consequently, the non-dimensionalised coordinates of each heliostat's centre position in the field were obtained. For the last 10 rows, the circumferential angles subtended by the end heliostats were measured and the heliostat positions were determined.

The same exercise was also performed for the other two plants, namely, PS 10 and PS 20 (see Fig. A.2a and A.3a). These two plants also have a radial staggered heliostat layout. However, they use cavity receivers and hence only have a single side (north) field.

Based on this exercise, the replicated fields (along with their originals) are shown from Fig. A.1 to A.3. It can be seen that the replicated field shows a very close comparison with the original images. This ascertains that the degree of error in the approximate measured radial distances is negligible.

\section{Gemasolar Plant}

In order to look at the variation of packing density with radial distance from the base of the tower, the packing density of each row of heliostats was computed. The radial distance of each row $(r)$ was measured. The first 27 rows are full circles. The last 10 rows (row 28 to 38) do not form complete 
circles. The angle subtended by the farthest two heliostats of each row plus half the circumferential angle between heliostats on each side was measured ( $\Delta \theta$ in radians). This is shown in Fig. A.4.

As an example, in order to find out the packing density of the $n^{\text {th }}$ row, with radial distance $r_{n}$ from the base of the tower, the following steps were followed (refer Fig. A.4).

1) Mirror area of this row $\left(M A_{n}\right)$ is calculated using Eq. A.2.

$M A_{n}=n_{n} \times A_{\text {heliostat }}$

where $n_{n}$ is the number of heliostats in the $n^{\text {th }}$ row and $A_{\text {heliostat }}$ is the area of each heliostat (which is constant).

2) Land area of this row $\left(L A_{n}\right)$ is taken as the area of the shaded region between the dotted circles (between the midpoints of the given row ( $n$ ) with its adjacent rows) as can be seen in Fig. A.4. Radial distance of the previous row, $r_{(n-1)}$ and that of the next row, $r_{(n+1)}$ are considered.

3) The respective radial distances $r_{n a}, r_{n b}$ and land area of this row $\left(L A_{n}\right)$ are calculated using Eq. A.3 and Eq. A.4.

$r_{n a}=\frac{r_{(n-1)}-r_{(n+1)}}{2}$ and $r_{n b}=\frac{r_{(n-1)}+r_{(n+1)}}{2}$

$L A_{n}=\left\{\Delta \theta\left(r_{n b}^{2}-r_{n a}^{2}\right)\right\} / 2$

$P D_{n}$, the packing density of the $n^{\text {th }}$ row is calculated using Eq. A.5.

$P D_{n}=\frac{M A_{n}}{L A_{n}}$

In this way, packing density for each row was computed. It may be noted that when the row is a complete circle, $\Delta \theta=2 \pi$, $\left(360^{\circ}\right)$.

\section{PS 10 and PS 20 Plants}

For these plants, packing density was calculated as was done for the last 10 rows of the Gemasolar plant (the subtended angle was measured and the corresponding land area was calculated for that row).

\section{Determination of Nominal Variation of Packing Density with $r / h$}

Fig. A.5 shows the packing density variation for the existing plants and the theoretical variation that was given in [19]. It may be seen, that this theoretical value is not in conformity with the existing practical data. Therefore to obtain a nominal packing density variation with $r / h$, data of the existing plants was used. It can be seen that from this data, at around $r / h=2$ and $r / h=4$, jumps occur (Fig. A.5). This happens because in the staggered pattern, the circumferential distance between heliostats increases as $r$ increases and at $\sim r / h=2$ and 4 , these distances become large enough to introduce additional heliostats between them. The radial gaps are also increased to avoid blockage effects. So, the local mirror area suddenly increases (for the next row) and the jump in packing density occurs. However, for defining the nominal packing density variation at point $p,(P D)_{p}$, jumps have been avoided and curve fits of the data were obtained as given as follows (Eq. A.6 to Eq. A.8):

$(P D)_{p}=0 \quad$ for $\frac{r}{h}<\left(\frac{r}{h}\right)_{\min }$ 


$$
\begin{aligned}
& (P D)_{p}=0.492-0.0939 \frac{r}{h} \quad \text { for }\left(\frac{r}{h}\right)_{\text {min }} \leq \frac{r}{h} \leq 2.8 \\
& (P D)_{p}=\frac{0.6}{\sqrt{\left(\frac{r}{h}\right)^{2}-1}} \quad \text { for } \frac{r}{h}>2.8
\end{aligned}
$$

It may be noted that packing density is mainly a function of $r / h$ and not dependent on the azimuth angle.

The equations mentioned above are used while taking into account variation of the packing density of heliostats in determination of the contours of annual solar energy per unit land area.

\section{References}

[1] Suresh N S, Thirumalai N C, Rao S Badri, Ramaswamy M A, 2014. Methodology for sizing the solar field for parabolic trough technology with thermal storage and hybridization. J. Sol. Energy. $110,247-259$.

[2] Burgaleta Juan Ignacio, Arias Santiago, Ramirez Diego, 2014. Gemasolar, The First Tower Thermosolar Commercial Plant with Molten Salt Storage. Solar Paces.

[3] Zunft Stefan, Hänel Matthias, Krüger Michael, Dreißigacker Volker, Göhring Felix, Wahl Eberhard, 2011. Jülich Solar Power Tower - Experimental Evaluation of the Storage Subsystem, and Performance Calculation. J. Sol. Engg. ASME. 133, 031019-1-5.

[4] Xu Ershu, Yu Qiang, Wang Zhifeng, Yang Chenyao, 2011. Modelling and Simulation of 1 MW DAHAN Solar Thermal Power Tower Plant. J. Renewable Energy. 36, 848-857.

[5] Quero M, Korzynietz R, Ebert M, Jimenez AA, Rio del A, Brioso JA, 2013. Solugas - Operation Experience of the First Solar Hybrid Gas Turbine System at MW scale. SolarPACES, Energy Procedia 00 (2013) 000-000.

[6] Wei Xiudong, Lu Zhenwu, Yu Weixing, Wang Zhifeng, 2010a. A New Code for the Design and Analysis of the Heliostat Field Layout for Power Tower System. J. Sol. Energy. 84, 685-690.

[7] Wei Xiudong, Lu Zhenwu, Wang Zhifeng, Yu Weixing, Zhang Hongxing, Yao Zhihao, 2010b. A New Method for the Design of the Heliostat Field Layout for Solar Tower Power Plant. J. Renew Energ. 35, 1970-1975.

[8] Pitz-Paal R, Botero Bayer Nicolas, Steinfeld Aldo, 2011. Heliostat Field Layout Optimization for High-Temperature Solar Thermochemical Processing. J. Sol. Energy. 85, 334-343.

[9] Noone J Corey, Manuel Torrilhon, Mitsos Alexander, 2012. Heliostat Field Optimization: A New Computationally Efficient Model and Biomimetric Layout. J. Sol. Energy. 86, 792-803.

[10] Sánchez-González and Santana D, 2015. Solar Flux Distribution on Central Receivers: A Projection Method from Analytic Function. J. Renew Energ. 74, 576-587.

[11] Salomé, A., Chhel, F., Flamant, G., Ferrière, A., \& Thiery, F, 2013. Control of the flux distribution on a solar tower receiver using an optimized aiming point strategy: Application to THEMIS solar tower. J. Sol. Energy, 94, 352-366.

[12] Belhomme B, Pitz-Paal R, Schwarzbözl P, Ulmer S, 2009. A New Fast Ray Tracing Tool for High Precision Simulation of Heliostat Fields. J. Sol. Energ-T ASME. 131, 031002-1-8. 
[13] Huang Weidong, Li Longlong, Li Yongping, Han Zhengfu, 2013. Development and Evaluation of Several Models for Precise and Fast Calculations of Shading and Blocking in Heliostat Field. J.

Sol. Energy. 95, 255-264.

[14] Kiera M and Schiel W, 1989. Measurement and Analysis of Heliostat Images. J. Sol. Energ-T ASME. 111, 2-9.

[15] Romero Manuel, Buck Reiner, Pacheco E James, 2002. An Update on Solar Central Receiver Systems, projects and Technologies, J. Sol. Energ-T ASME. 124, 98-108.

[16] Srilakshmi Gopalakrishnan, Venkatesh V, Thirumalai N C, Suresh N S, 2015. Challenges and Opportunities for Solar Tower Technology in India. J. Renew Sust Energ. Rev. 45, 698-709.

[17] VANT-HULL L L, and Izygon M E, 2003. Guideline to Central Receiver System Heliostat Field Optimization. Advances in Solar Energy, 15, 1-42.

[18] Solar Advisory Model (SAM), National Renewable Energy Laboratory (NREL). URL: https://sam.nrel.gov/. Last Accessed: June 2016.

[19] William Stine and Michael Geyer. Power from the Sun. Chapter 10: Central Receiver Systems. URL: http://www.powerfromthesun.net/. Last Accessed November 2015.

[20] M A Ramaswamy, Gopalakrishnan Srilakshmi, N S Suresh, N C Thirumalai, 2015. Design of Solar Field and Performance Estimation of Solar Tower Plants. Center for Study of Science Technology and Policy (CSTEP).

[21] National Renewable Energy Laboratory (NREL), 2015.

http://www.nrel.gov/csp/solarpaces/power tower.cfm. Last Accessed: February 2016.

[22] Wikimapia, 2015a. Gemasolar Plant. http://wikimapia.org/\#lang=en\&lat=37.564548\&lon=5.326610\&z=15\&m=b. Last Accessed: November 2015.

[23] Wikimapia 2015b. PS 10 and PS 20 Plants.

http://wikimapia.org/\#lang=en\&lat=37.445153\&lon=-6.255856\&z=16\&m=b. Last Accessed:

November 2015. 


\section{LIST OF FIGURES}

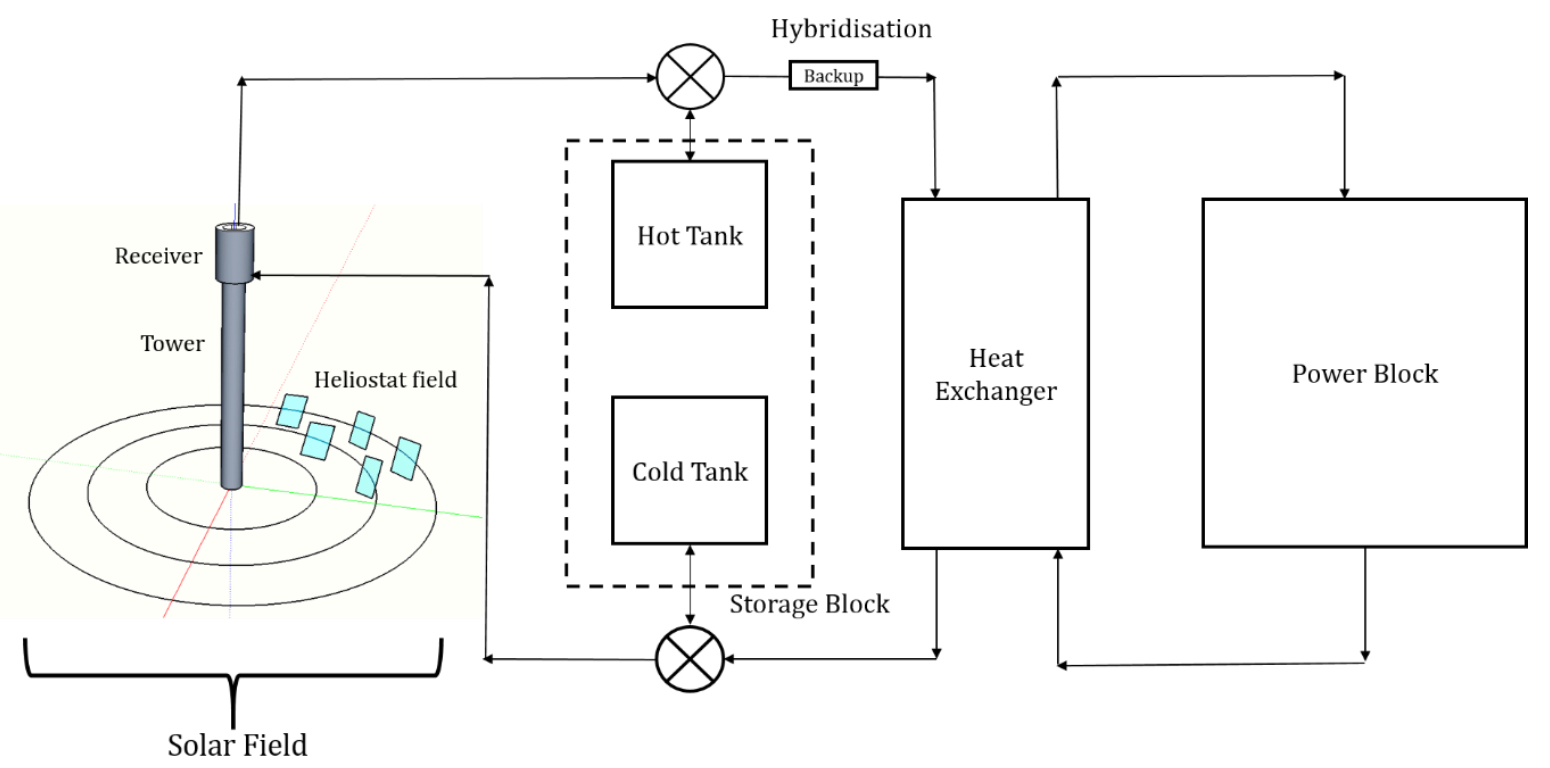

Fig. 1: Schematic of Solar Tower Plant

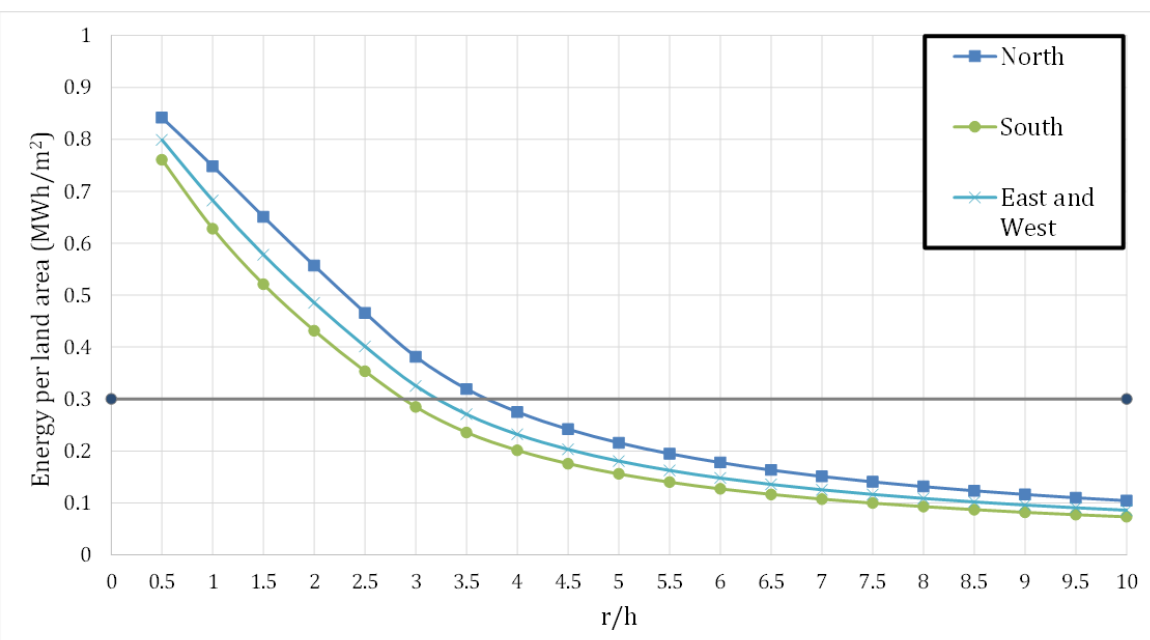

Fig. 2: Variation of $e_{l}$ with $r / h$ in all Four Directions 


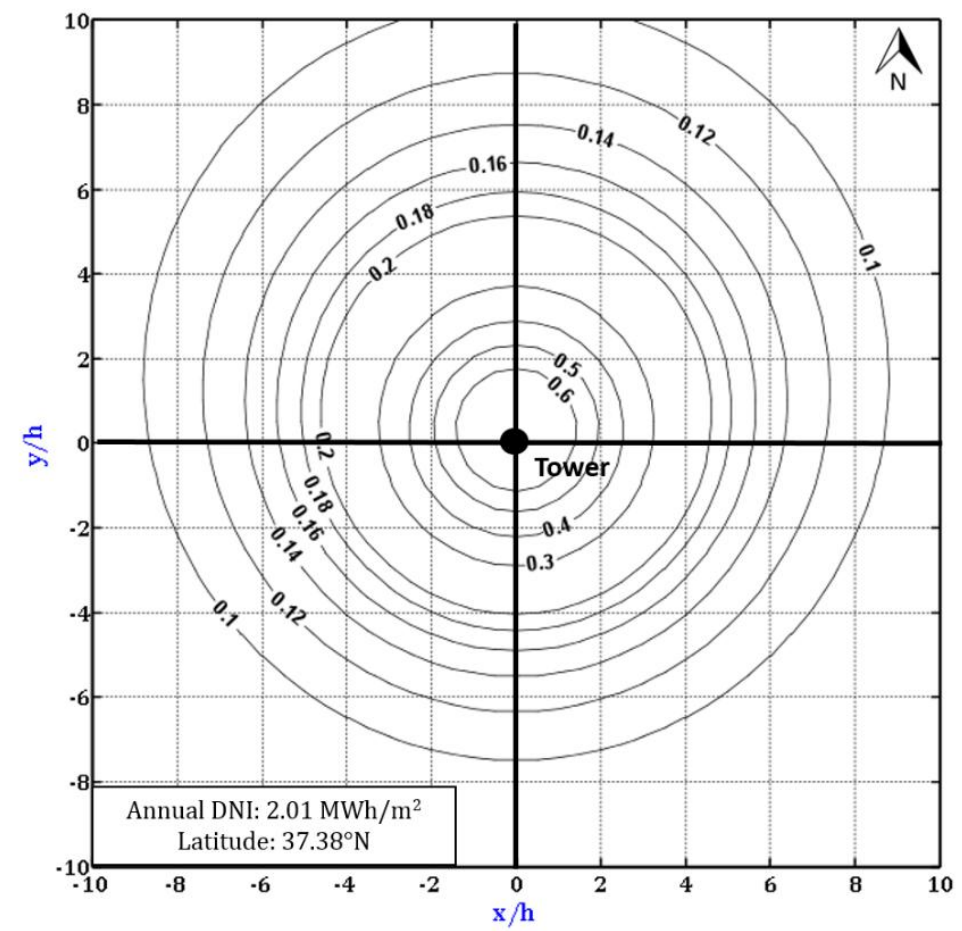

Fig. 3: Equal annual energy contours per unit land area $\left(\mathrm{MWh} / \mathrm{m}^{2}\right)$ for Seville

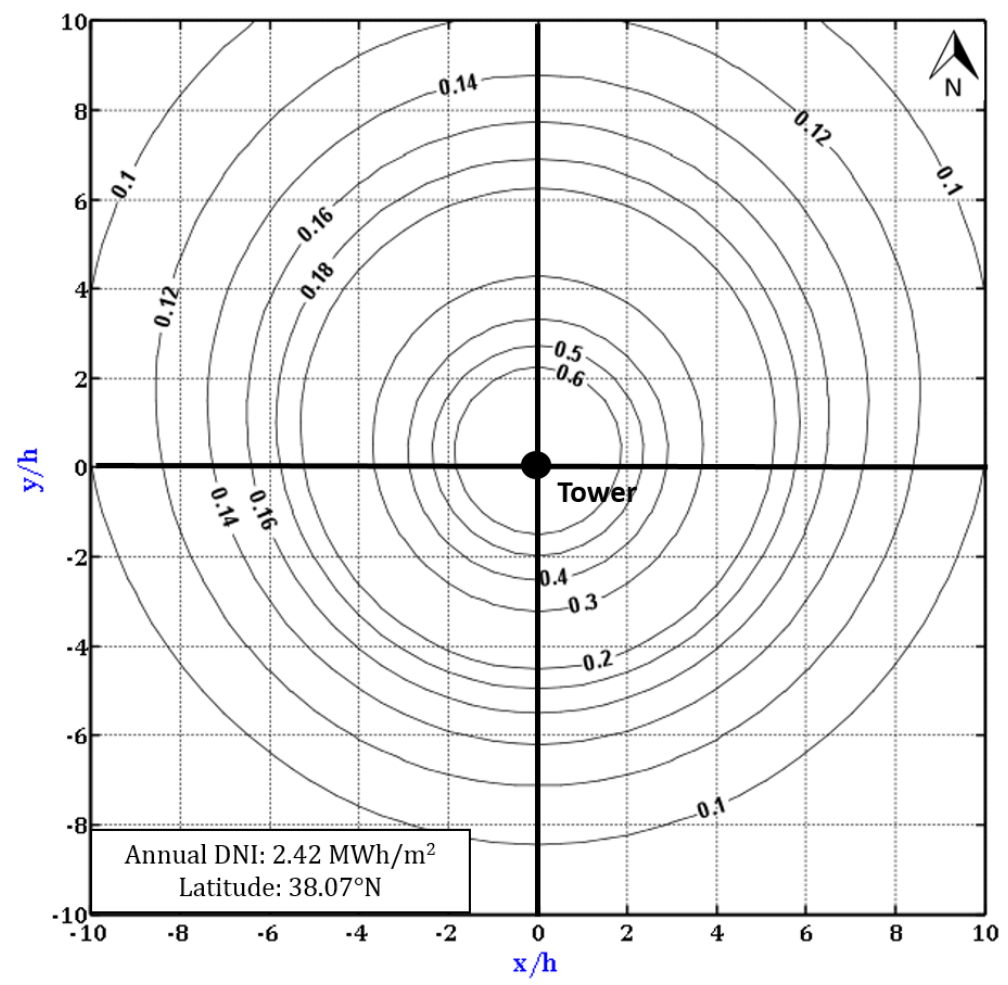

Fig. 4: Equal annual energy contours per unit land area $\left(\mathrm{MWh} / \mathrm{m}^{2}\right)$ for Tonopah 


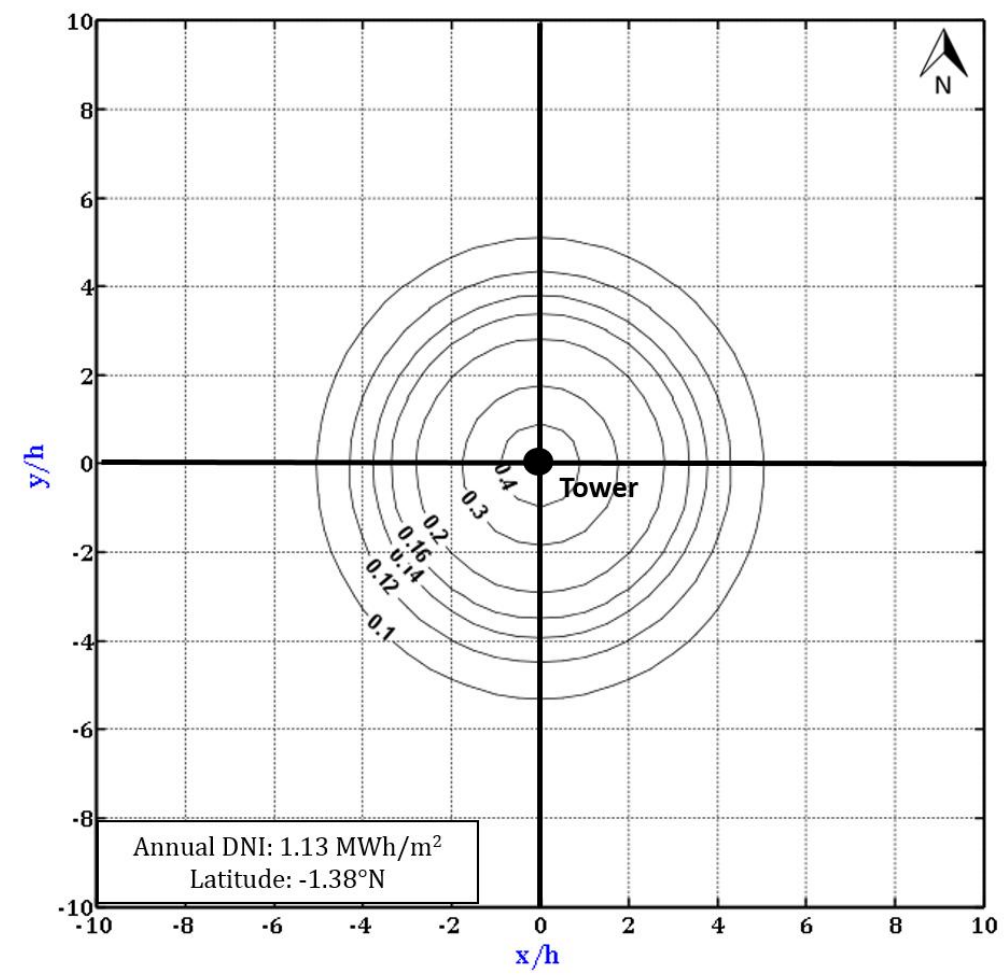

Fig. 5. Equal annual energy contours per unit land area $\left(\mathrm{MWh} / \mathrm{m}^{2}\right)$ for Brazil

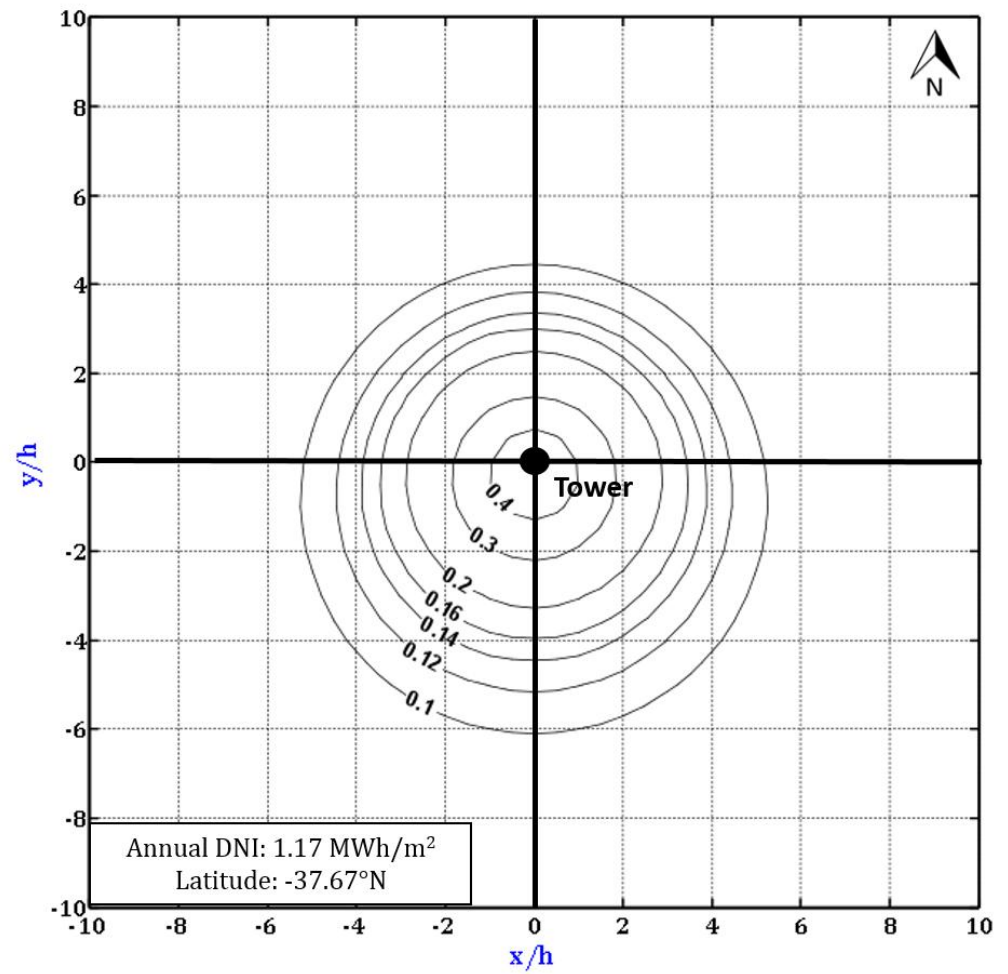

Fig. 6: Equal annual energy contours per unit land area $\left(\mathrm{MWh} / \mathrm{m}^{2}\right)$ for Melbourne 


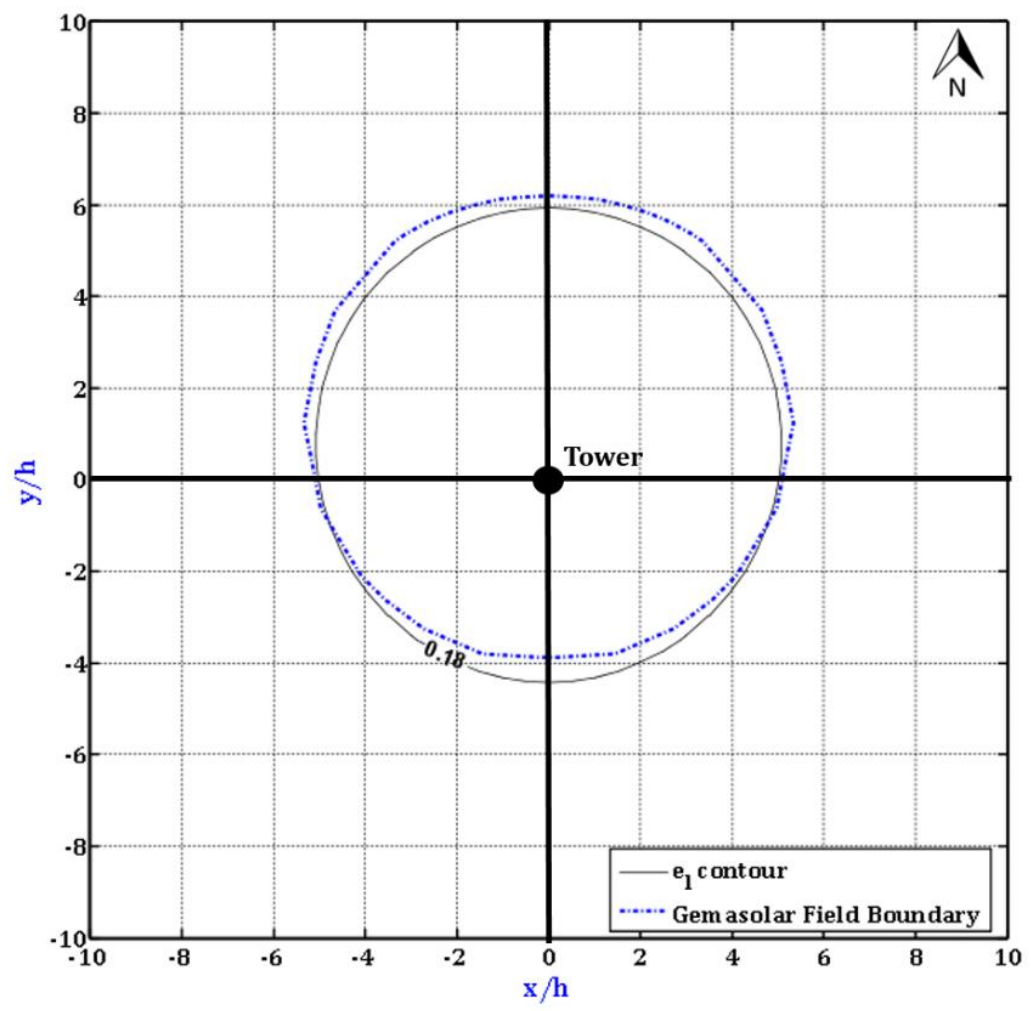

Fig. 7: Gemasolar Field Boundary and $e_{l}$ field contour at Seville

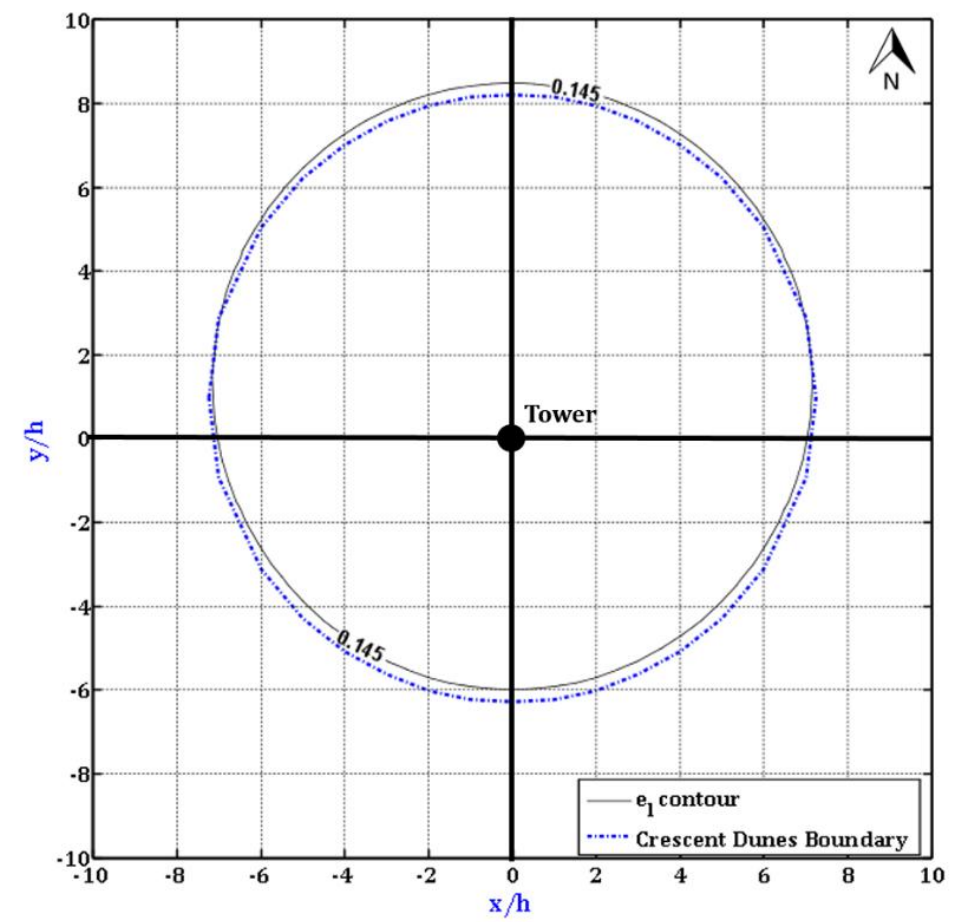

Fig 8: Crescent Dunes Field Boundary and $e_{l}$ field contour at Tonopah 


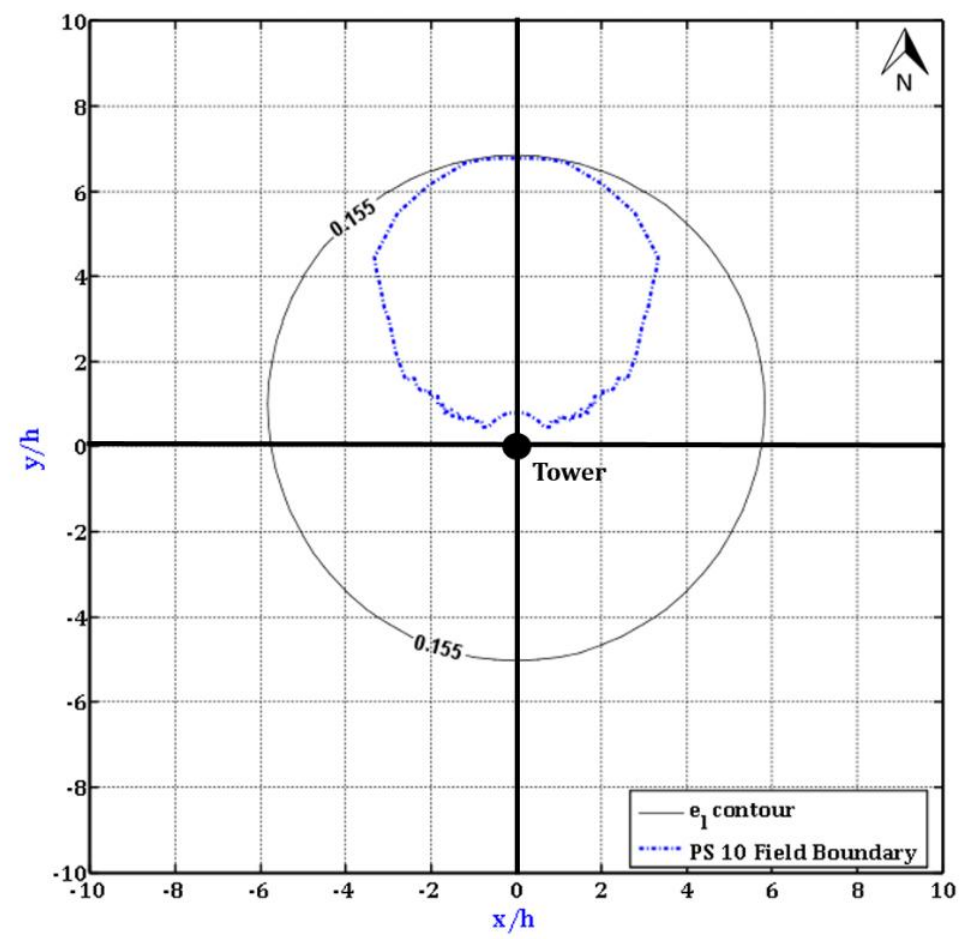

Fig.9: PS 10 Field Boundary and $e_{l}$ field contour at Seville

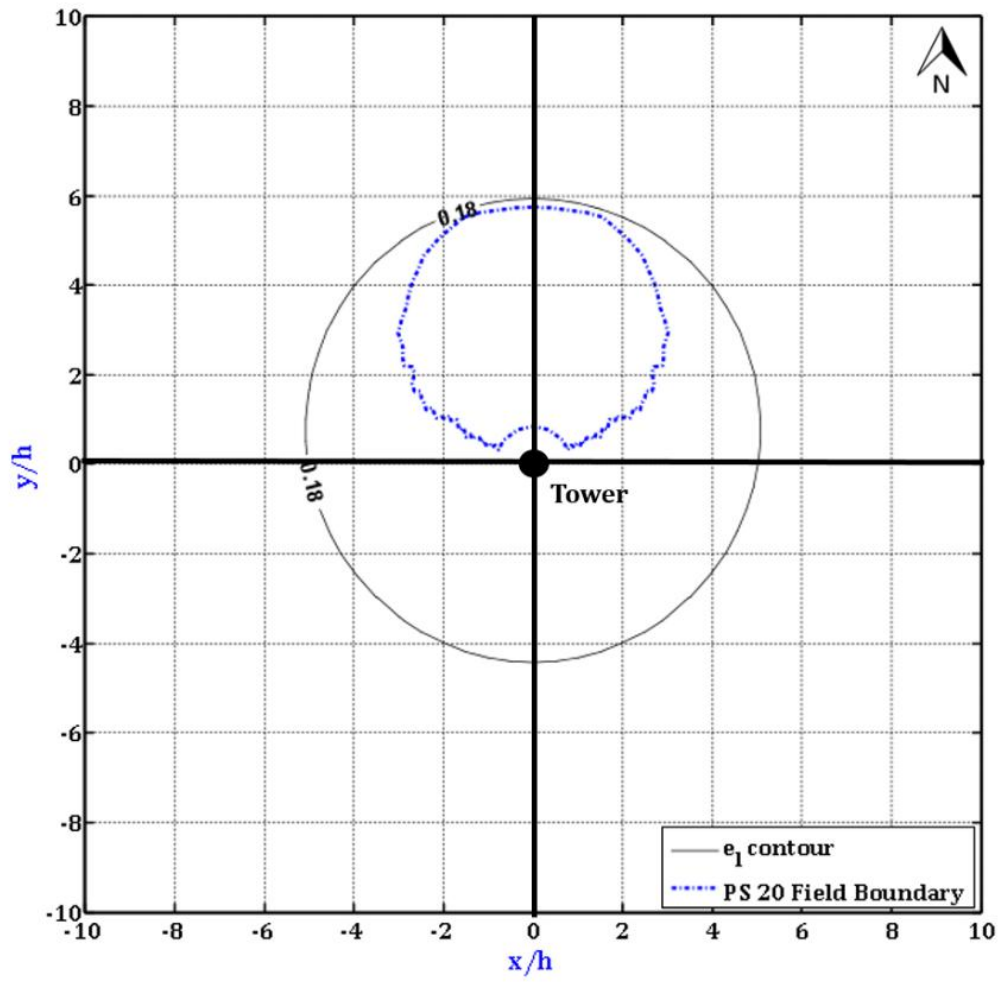

Fig. 10: PS 20 Field Boundary and $e_{l}$ field contour at Seville 


\section{FIGURES FOR APPENDIX}

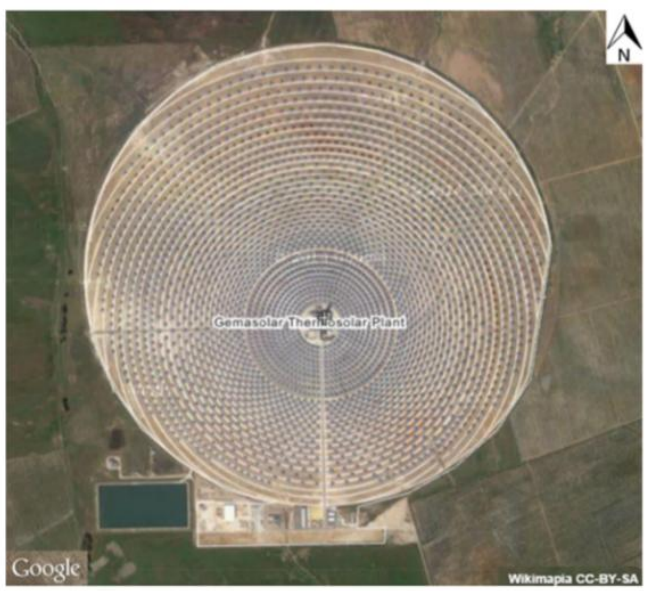

a) From Wikimapia

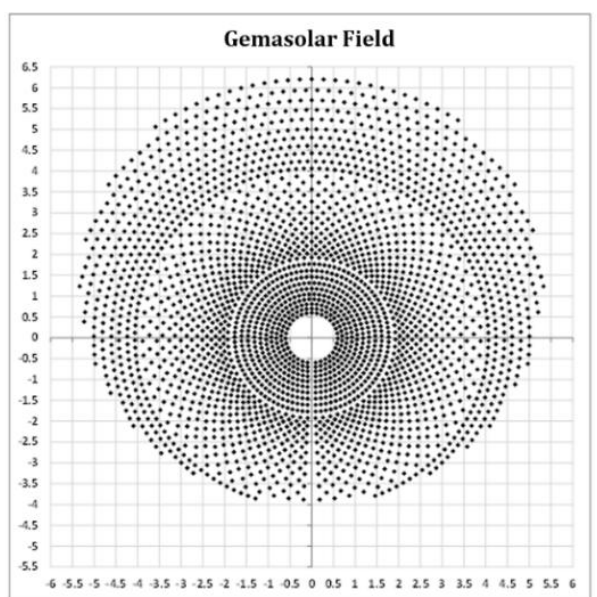

b) Replication

Fig. A.1: Replication of Gemasolar Field in Excel (comparison)

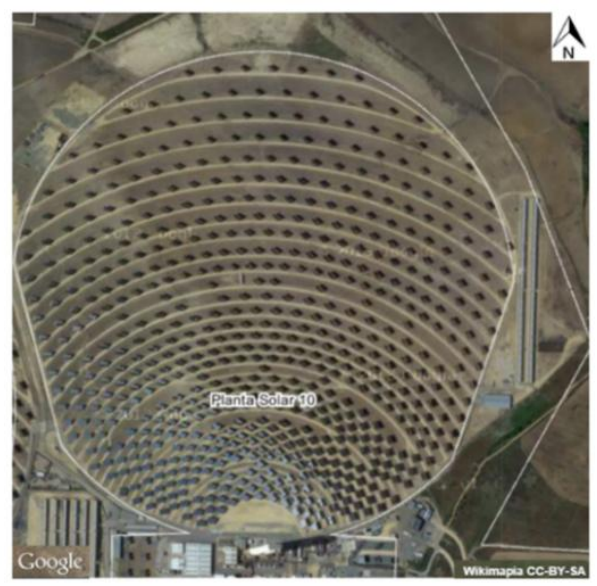

a) From Wikimapia

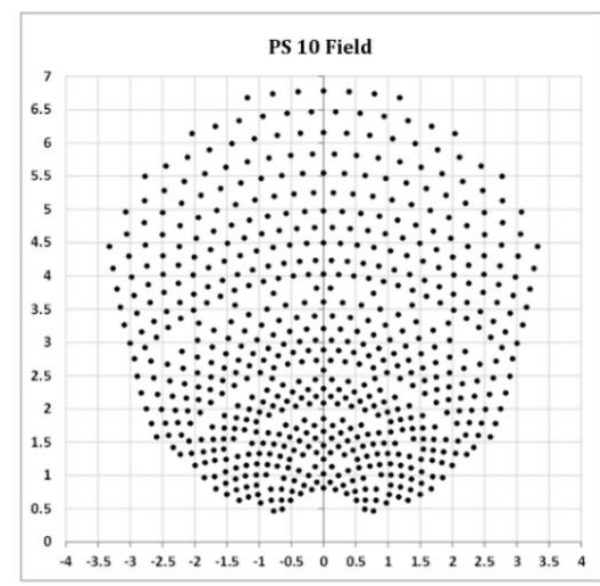

b) Replication

Fig. A.2: Replication of PS 10 Field in Excel (comparison)

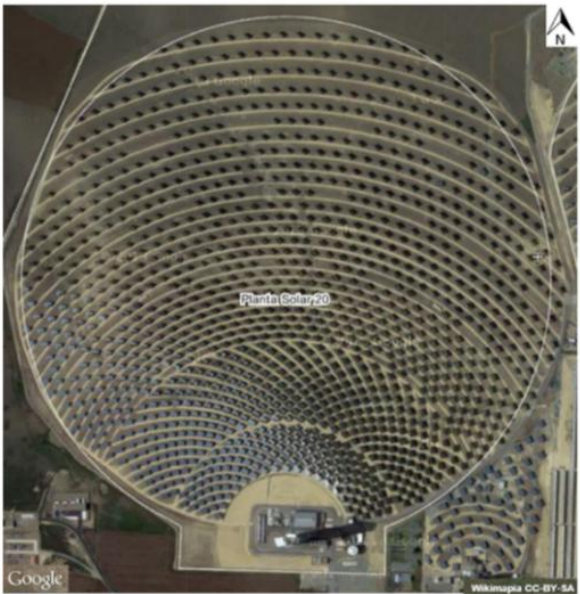

a) From Wikimapia

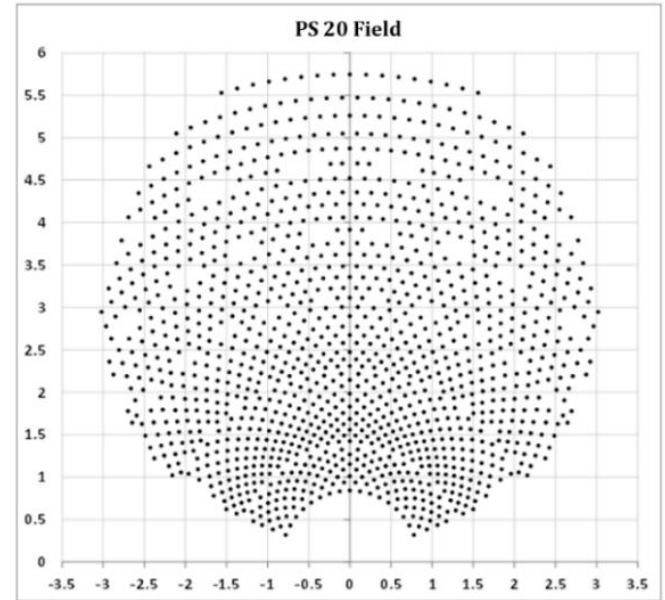

b) Replication

Fig. A.3: Replication of PS 20 Field in Excel (comparison) 


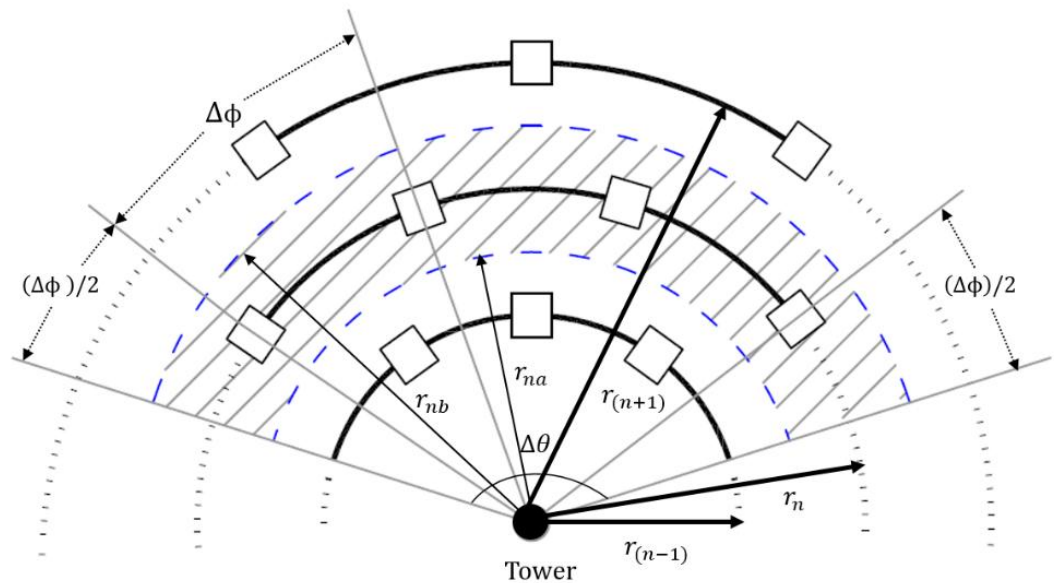

Fig. A.4: Local Packing Density Determination

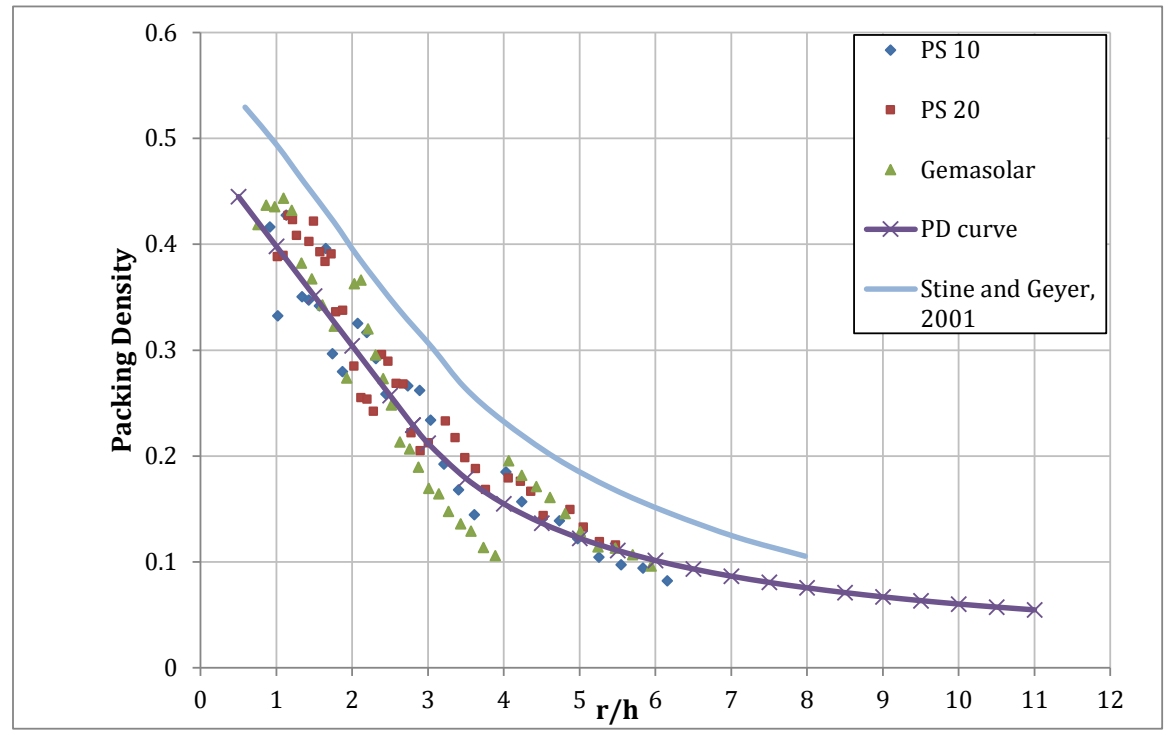

Fig. A.5: Curve Fits Chosen to Account for Packing Density 